\title{
Poezja języka migowego jako czynnik kulturotwórczy
}

\section{Sign language poetry as a factor which create the culture}

Aleksandra Rąbel

(Wroclaw)

\begin{abstract}
In the paper there are presented different forms of sign language poetry. They are created by the Deaf, a language and culture minority, using the natural sign language. They are also forms of games and activities and thus create a culture of deaf community. In addition, each of the described forms of poetry is refered to the Roger Caillois's conception of a paidialudus axis.
\end{abstract}

Postawa ludyczna musiała istnieć już, zanim powstała kultura ludzka czy też ludzkie zasoby mowy i wyrazu. Johan Huizinga, Homo ludens

Naturalny język migowy osób kulturowo Gluchych ${ }^{1}$ spelnia nie tylko podstawową funkcję języka - funkcję komunikatywną; stanowi również doskonale narzędzie ekspresji, wykorzystywane przez Głuchych w akcie tworzenia poezji języka migowego.

Johan Huizinga zwraca uwagę na

1 „Głusi”, pisani wielką litera, to określenie społeczności językowej i kulturowej. natomiast ,głusi" to ludzie ze znaczacym ubytkiem słuchu, nazywani tak z medycznego punktu widzenia. Terminologia ta przyjęta jest w środowisku Gluchych (za: Świdziński 2005). 
konieczność pozbycia się poglądu, iż poezja ma jedynie funkcję estetyczną, względnie iż jedynie na podstawie założeń estetycznych można ją wyjaśnić lub zrozumieć. We wszelkiej kwitnacej, żywej kulturze, a przede wszystkim w kulturach archaicznych, poezja jest funkcją życiowa, społeczną i liturgiczną. Wszelka stara poezja jest jednocześnie i zarówno: kultem, odświętną uciechą, grą towarzyską, sprawnością, próbą lub zagadka, mądrym pouczeniem, perswazją, oczarowaniem, wróżba, proroctwem i rywalizacja." (Huizinga 1985: 173).

Spośród tych określeń najtrafniejsze są według mnie: uciecha, gra towarzyska, sprawność, próba, perswazja, oczarowanie. Odnosza się one jednak do różnych typów poezji migowej. Sfera określeń powiązanych z kultem jest natomiast, moim zdaniem, nieadekwatna do poezji tworzonej przez Gluchych.

Glównym problemem czy też zadaniem przed jakim stoi spoleczność Gluchych, zwlaszcza w Polsce, jest popularyzacja naturalnego języka migowego (w Polsce - polskiego języka migowego - PJM-u) i kultury Gluchych. Wokól niego skupia się zatem tematyka bądź też formalna realizacja ich poezji. Nawet wiersze w języku fonicznym, spisane przez Gluchych poetów, nienależące jednak do poezji migowej sensu stricto, podejmują w zdecydowanej większości tematy ciszy i rąk, co świadczy o istotności tego typu problematyki dla środowiska Gluchych (zob. Kowal 2008).

Poezja języka migowego nie poddaje się bowiem regułom rządzacym poezją w językach fonicznych. Warto zauważyć przy tej okazji jak bardzo odmienne są wiersze pisane w różnych językach ze względu na kontekst językowy, historyczny i kulturowy, by uświadomić sobie przyczyny odmienności poezji migowej jako naturalnego następstwa wykorzystywania przez Gluchych innego kanalu - modalności wzrokowej, a nie sluchowej, w procesie komunikacji. Z calą pewnościąjednak jest ona ważna dla spoleczności Gluchych, stwarza i świadczy o ich kulturze.

Badacze języków migowych uciekają się do porównań obu typów poezji - mówionej i migowej -- glównie, moim zdaniem, ze względu na podobną funkcję pelnioną przez takie utwory w kulturze. Analogiczne elementy to $\mathrm{m}$. in. podobny ksztalt dloni jako 
wyznacznik aliteracji ${ }^{2}$ i rymu, przeplyw i rytm znaków na zasadzie podobieństwa do linii melodycznej w poezji mówionej, manipulacja lokacja i ruchem znaków w celu uzyskania spójności i ciaglości, nachodzenie, wydlużanie lub skracanie znaków po to, by stworzyć wzorzec rytmiczny (za: Corina/Hildebrandt 2000) ${ }^{3}$. Interesujące jest ponadto rozróżnianie w polskim języku migowym osobnych znaków dla poezji mówionej i poezji migowej.

Zliczmy raz jeszcze wszystko, co wydaje się stanowić właściwe cechy zabawy lub gry. Jest to działanie, przebiegające w obrębie pewnych granic czasu, przestrzeni i sensu, w widocznym porządku, wedhug dobrowolnie przyjętych regul, poza sferą materialnej użyteczności czy też konieczności. (...) Ten, kto nazywa poezję grą stów i mowy (...) nie posluguje się bynajmniej znaczeniową przenośnią, lecz oddaje istotny sens slowa (Huizinga 1985: 190).

Badacz poezji migowej określi ją raczej jako gra rak, gestów i mimiki.

Idac tropem Huizingi natrafiamy na podzial gier i zabaw wedhug Cailloisa. Większość typów poezji migowej należy, wedlug mnie, do gatunku mimicry, lecz ciekawsze jest sformulowanie twierdzenia o dwóch biegunach, między którymi sytuują się wszystkie gatunki gier i zabaw. Na jednym krańcu - paidia, określana jako ,wspólna zasada rozrywki, rozpasania, swobodnej improwizacji i beztroski" (Caillois 2005: 164), na drugim - ludus - ,potrzeba podporzadkowania spontaniczności pewnym konwencjom arbitralnym, (...) wymaga coraz więcej wysiłku, zręczności, pomysłowości" (Caillois 2005: 164). Obie tendencje znajdują odzwierciedlenie w poezji migowej. $Z$ jednej strony bowiem improwizacja pełni w niej szczególną rolę (zwlaszcza że przed epoką upowszechnienia się sprzętu nagrywajacego miała charakter jedynie jednorazowy), z drugiej - sformulowano wyznaczniki piękna poezji - jej kompozycji wizualnej (tj .

2 Anglosaska aliteracja (alliteration) rozumiana jest jako powtarzalność podobnej spólgloski inicjalnej w kolejnych słowach Corina, Hildebrandt 2000.

3 Podobne obserwacje, już na gruncie polskiego języka migowego - Bielak (2007). 
wielkość, ksztalt, struktura przestrzeni) i tzw. profilów idealnych (zarysy dloni, symetria, dynamika) (Bielak/Świdziński 2006). Rację ma zatem Caillois:

Tego rodzaju pierwotny dar improwizacji i uciechy, który określam slowem paidia, idac w parze $\mathrm{z}$ upodobaniem do bezinteresownego wysilku, nazwanego przeze mnie ludus, prowadzi do powstania różnego rodzaju gier i zabaw, którym, nie popadając w przesadę, można przypisać walor kulturotwórczy (Caillois 2005: 169).

Przestawię teraz krótką charakterystykę poszczególnych typów poezji migowej, z uwzględnieniem ich wlaściwości kulturotwórczych. Opisywać będę reguly ich tworzenia, gdyż sa one ,nieodlączną częścią zabawy, gdy tylko zyskuje ona (...) egzystencję instytucjonalną. Od tej chwili stanowią one część jej istoty i one wlaśnie przeksztalcają zabawę w plodne i ważne narzędzie kultury" (Caillois 2005: 168).

Pierwszym rodzajem jest poezja ABC. Tworzy się ją poprzez reprezentację bądź naśladownictwo idei, pojęcia $\mathrm{z}$ wykorzystaniem liter alfabetu palcowego. Na przyklad wiersz pod tytulem „Kot” zamiga się oddając cechy wyglądu zewnętrznego, charakteru kota (często na zasadzie skojarzeń) używając w tym celu liter K, O, T i każdej przypisując część opowiadanej historii (np. jedną cechę) (por. Bielak Swidziński 2006; Kowal 2008).

Poezja liczbowa (123) jest natomiast przedstawianiem pojęć za pomoca kolejnych liczb (znaków liczebnikowych). Sama więc forma konotuje skojarzenie, że historia opowiadana rozwija się - bądź to jako przechodzenie od cech narzucajacych się w pierwszym momencie do tych bardziej skomplikowanych, bądź - tworzy coś w rodzaju fabuly.

Ze względu na te cechy bardzo upodabniają się oba opisane przeze mnie do tej pory typy do mimicry i oczywiście, jak każda poezja migowa, do pantomimy. Na naśladownictwo jako ważny element kultury wskazuje Skórzyńska: 
Dzięki naśladownictwu pantomima spełniala cele praktyczne, socjalizujace i estety czne, które z czasem dopiero zaczęly być realizowane w odrębnych praktykach społecznych. Zgodnie z zalożeniami Richarda Schechnera podzialy na widowiska o charakterze rytualnym i estetycznym nie są sztywne i mają charakter relatywny kulturowo (Skórzyńska 2007: 70).

Wydaje się zatem, że zarówno poezja $\mathrm{ABC}$, jak i poezja 123 nie przejawiają funkcji rytualnej, są natomiast formą gry językowej i mieszczą się gdzieś pośrodku osi paidia-ludus.

Następnym typem poezji migowej jest tzw. poezja duszy. Sa to utwory migane jednym ukladem dloni, w większym stopniu impresyjne niż te poprzednio opisane. Umieścilibyśmy ją zatem bliżej bieguna paidia ze względu na jej charakter improwizacyjny, zależny od stanu emocjonalnego, jaki autor (wykonawca) chce przekazać. $Z$ drugiej strony jednak, obecne sa elementy ludus - można się tu nawet dopatrywać chęci sięgania do tradycji studia teatralnego. Jak pisze Skórzyńska: „W praktyce teatralnej zaowocowalo to powstaniem metod twórczych, w których permanentny trening przedklada się nad realizację konkretnego spektaklu, a etos pracy i poszukiwanie nowych dróg rozwoju nad sukces artystyczny" (Skórzyńska 2007: 72).

Warto przy tej okazji dodać, że tak samo, jak w przypadku poezji w językach fonicznych, wybór takiego a nie innego typu poezji pociaga za soba odpowiednie konotacje. Zatem, jak na przyklad w siedemnastowiecznej poezji polskiej wybór jedenastozgloskowca jako formy wiersza sygnalizowal kulturę wysoka. literackość poprzez skojarzenia z tak wlaśnie postrzeganą poezją włoską (za: Pszczolowska 2002: 276), tak wybranie jednego z typów poezji migowej świadczy o sięganiu do określonej tradycji. I tak - poezja $\mathrm{ABC}$ najczęściej kojarzy się z dziecięcymi rymowankami, poezja 123 uważana jest już za bardziej skomplikowana, a poezja duszy odbiera się jako głęboko artystyczną (zob. Kowal 2008).

Tym natomiast, co wyróżnia poezję migowajest zjawisko poezji grupowej. Utwory tworzone są wspólnymi siłami uczestników zabawy - autorów. Sięgają oni po jedna z technik poetyckich, często 
poezję ABC i współdzialając kreują literacką rzeczywistość. Taką aktywność językowa można interpretować jako odbicie charakteru spoleczności Gluchych, dążacej do zjednoczenia i podtrzymania kultury w imię „obrony” przed calkowitą asymilacją ze slyszącymi. Ponadto:

Gry i zabawy zazwyczaj osiagaja pełnię dopiero w chwili, gdy budza jakiśs oddźwięk, wspóldzialanie. Nawet wówczas, gdy w zasadzie grający mogliby doskonale bawić się na wlasną rękę, zabawy czy gry rychlo stają się pretekstem do zawodów czy widowisk (Caillois 2005: 170).

Zawody mogłyby w poezji migowej przybierać formę dążenia do oryginalności skojarzeń i ekspresywności wykonania.

Swego rodzaju poezją grupowa jest także poezja biesiadna. Są to spontaniczne historyjki o bardzo luźnej konstrukcji, nieukładajace się często w żadną logiczną fabułę. Jak sama nazwa wskazuje, tworzenie jej odbywa się na różnego rodzaju imprezach, a im większy poziom rozemocjonowania uczestników zabawy, tym fabula historii bardziej absurdalna. Jedną z form poezji biesiadnej jest takie prowadzenie akcji (wyznaczane rytmem np. rytmicznymi przejściami między znakami) tak, by chwilę wlasnej zabawy językiem zakończyć zamiganiem czyjegoś znaku migowego ${ }^{4}$. To stanowi sygnal, że wlaśnie ta osoba wywolana jest, aby historię kontynuować. Jak widać, właśnie ten typ poezji migowej ma najwięcej wspólnego z paidiq. Kto wie, czy nie powinniśmy oczekiwać wkrótce podobnego przejścia poezji biesiadnej $w$ formy parateatralne, tak jak miało to miejsce z dramatami greckimi, tworzonymi pierwotnie ku uciesze bogów („Nastrój dramatu jest nastrojem dionizyjskiej zabawy, odświętnego upojenia i dytyrambicznego zachwytu" (o dramacie Ajschylosa - zob. Huizinga 1985: 207)).

Ostatnim z wyróżnionych przez Kowal (Kowal 2008) typów poezji migowej jest poezja zaangażowana. Najczęściej przybiera

4 Znak migowy (imię migowe) przypisywany jest każdemu wchodzącemu do spoleczności Gluchych, także uczacym się języka migowego. Pochodzi najczęściej od nazwiska, bądź jakiejś cechy wyglądu czy charakteru i w ciągu życia może ulegać zmianom. 
ona formę migania - thumaczenia piosenki, której przesłanie to walka z dyskryminacja Głuchych i propagujacymi język migowy. Przyklady można znaleźć w Internecie - sa to np. teledyski D-Pan (Deaf Performing Artists Network) ${ }^{5}$. Stanowi ona zatem najbardziej wyrazisty dowód na znaczenie poezji migowej w procesie tworzenia kultury Głuchych, ponieważ, jak twierdzi Caillois, jeśli „gry i zabawy są czynnikiem kulturotwórczym, a zarazem obrazem kultury, wynikałoby z tego poniekad, że dana cywilizację, a w ramach tej cywilizacji jakaśs epokę, można by scharakteryzować na podstawie wlaściwych jej gier i zabaw" (Caillois 2005: 172). Calości kultury Gluchych nie da się opisać na podstawie poezji, ale tylko dlatego, że nie jest to jedyna istniejąca w tej społeczności forma zabawy.

Nie ulega jednak watpliwości, że poezja migowa jest ważnym elementem kultury Gluchych, spaja ja i umacnia. Tworzenie jej sprawia wiele radości. Na potwierdzenie moich slów zacytuję Gluchego, jednego z uczestników obozu PJM w Świnoujściu 6 , który pisze na swoim blogu:

My, i uczestnicy i goście wieczorem poszliśmy do jednego baru na plaży bardzo blisko morza - usiedliśmy razem przy piwie, trzaskaliśmy dlońmi o stól i wybieraliśmy przydomek migowy każdego uczestnika. Akurat jeszcze już było późno, niektórzy byli zmęczeni, my Glusi zostaliśmy dlużej i stworzyliśmy szaloną poezję ze znakami migowymi każdego, kto w tym się bawił. Było to szalenie dużo improwizacji w poezji pejomowej. Pozostaly nam tylko mile wspomnienia $(. .)^{7}$.

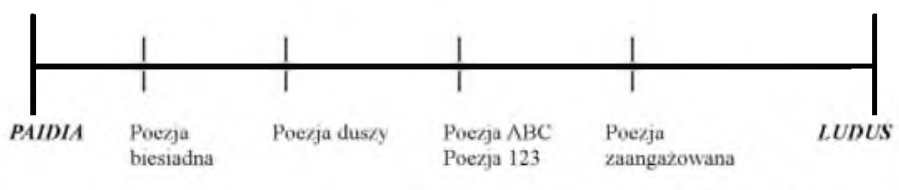

Źródlo: www.d-pan.com

6 Obóz PJM w Świnoujściu (18-27.08.2008) zorganizowany został przez Studenckie Koło Językoznawców Uniwersytetu Wroclawskiego.

7 Pisownia oryginalna. Źródło: http://deaf-piotrus-pan.blogspot.com/2008/08/ kolejny-obz-pjm-tym-razem-winoujcie 


\section{Bibliografia}

Bielak, Magdalena (2007): „Poezja w Polskim Języku Migowym” [referat na konferencji Milczacy cudzoziemcy. Glusi-Język-Kultura, Wrocław; tom pokonferencyjny w przygotowaniu].

Bielak, Małgorzata/Świdziński, Marek (2006): „Poezja w języku migowym" [wykład wygłoszony na X Festiwalu Nauki, Warszawa $15-24.09 .2006]$.

Caillois, Roger (2005): „Gry i ludzie”, [w:] Kolankiewicz Leszek (red.): Antropologia widowisk. Zagadnienia i wybór tekstów. Warszawa: Wydawnictwa Uniwersytetu Warszawskiego, s. 163-174.

Corina, David P./Hildebrandt, Ursula C. (2002): „Psycholinguistic investigations at phonological stucture in ASL". [w:] Meier Richard i in.: Modality and Structure in Signed and Spoken Languages. Cambridge: Cambrige University Press, 88-111.

Huizinga, Johan (1985): Homo ludens: zabawa jako źródto kultury. Warszawa: „Czytelnik".

Kowal, Justyna (2008): „Poezja i humor Gluchych” [wyklad wygloszony na XI Dolnośląskim Festiwalu Nauki dn. 20.09.2008].

Pszczołowska, Lucylla (2002): „Semantyka form wierszowych”. [w:] Tejże: Wiersz - styl-poetyka. Kraków: Univeritas, 268-285.

Skórzyńska, Agata (2007): „Mimicry jako laboratorium tożsamości refleksyjnej. Zabawa - teatr - sieć", [w:] Surdyk, Augustyn/Szeja, Jerzy (red.): Kulturotwórcza funkcja gier. Gra jako medium, tekst i rytual, t.2. Poznań: Wydawnictwo Naukowe Uniwersytetu im. Adama Mickiewicza, 69-78.

Świdziński, Marek (2005): „Języki migowe”, [w:] Galkowski Tadeusz/ Szelag Elżbieta/Jastrzębowska Grażyna (red.) Podstawy neurologopedii: podręcznik akademicki, Opole: Wydawnictwo Uniwersytetu Opolskiego, 679-692.

Tomaszewski, Piotr (2004): „Polski Język Migowy - mity i fakty”. Poradnik Językowy 6, 59-72.

http://deaf-piotrus-pan.blogspot.com/2008/08/kolejny-obz-pjm-tymrazem-winoujcie [25.05.2009]

www.d-pan.com [15.05.2009] 